\title{
Strategi Marketing Pada CV. Kembar Jaya Kreatif Dengan Memanfaatkan Analisis Swot Serta QSPM
}

\author{
Tradiga Nur Aziz ${ }^{1}$, Muhamad Rizal $^{2}$, Ria Arifianti ${ }^{3}$, Asmaul Husna ${ }^{4}$ \\ ${ }^{123}$ Program Magister Administrasi Bisnis Universitas Padjajaran, Bandung, Jawa Barat, Indonesia \\ ${ }^{4}$ Fakultas Ekonomi, Universitas Maritim Raja Ali Haji, Tanjungpinang, Indonesia
}

\begin{abstract}
ABSTRAK : CV. Kembar Jaya Kreatif ialah suatu industri yang bergerak di bidang garment ataupun konveksi. Hasil pemasukan CV. Kembar Jaya Kreatif pada bulan September 2017 hingga bulan April 2019 bisa dilihat jika terdapat sebagian bulan pemasukan yang tidak penuhi sasaran pemasukan yang telah didetetapkan. Sebab itu CV. Kembar Jaya Kreatif wajib merancang strategi baru agar tingkatkan pemasukan supaya dapat menggapai sasaran yang telah didetetapkan. Analisis SWOT digunakan buat memperoleh alternatif strategi, dimana alternatif strategi didapat dari aspek internal serta aspek eksternal industri. Informasi serta data riset terdiri dari informasi primer serta informasi sekunder, perlengkapan analisis yang digunakan dalam riset ini merupakan matriks IFE (Internal Factor Evaluation), matriks EFE (External Factor Evaluation), matriks IE (Internal- External), matriks SWOT (Strengths, Weakness, Opportunities, and Threats), serta QSPM (Quantitative Strategic Planning Matrix). Matriks SWOT menciptakan 5 alternatif strategi yang bisa diimplementasikan industri. Bersumber pada hasil QSPM dari 5 alternatif ada salah satu alternatif strategi yang diprioritaskan ialah menggunakan teknologi yang terdapat buat melaksanakan aktivitas pemasaran serta menjual produk secara online semacam lewat media sosial serta $e$ commerce dengan nilai skor TAS sebesar 6, 303.
\end{abstract}

Kata kunci: Strategi pemasaran, SWOT, QSPM

\begin{abstract}
CV. Kembar Jaya Kreatif is an industry engaged in garment or convection. The results of the CV. Kembar Jaya Kreatif from September 2017 to April 2019 can be seen if there are some months of income that do not meet the income target that has been set. Therefore CV. Kembar Jaya Kreatif is obliged to devise a new strategy in order to increase income in order to achieve the targets that have been set. SWOT analysis is used to obtain alternative strategies, where strategic alternatives are obtained from internal and external aspects of the industry. Information and research data consist of primary and secondary information, the analytical tools used in this research are the IFE (Internal Factor Evaluation) matrix, the EFE (External Factor Evaluation) matrix, the IE (Internal-External) matrix, the SWOT matrix (Strengths, Weakness)., Opportunities, and Threats), as well as QSPM (Quantitative Strategic Planning Matrix). The SWOT matrix creates 5 strategic alternatives that can be implemented by the industry. Based on the QSPM results from 5 alternatives, one of the prioritized alternative strategies is to use existing technology to carry out marketing activities and sell products online such as through social media and e-commerce with a TAS score of 6, 303.
\end{abstract}

Keywords: Marketing strategy, SWOT, QSPM

Email: tradiga20001@mail.unpad.ac.id ${ }^{1}$,muhamad.rizal@unpad.ac.id ${ }^{2}$, ria.arifianti@unpad.ac.id ${ }^{3}$, asmaulhusna@umrah.ac.id ${ }^{4}$

\section{Pendahuluan}

Di Indonesia disaat ini banyak bermunculan industri yang bergerak di bidang industri konveksi. Dalam perkembangannya perusahaan- perusahaan alami 
persaingan yang sangatlah ketat diantara mereka yang memproduksi produk sejenis. Perubahanperubahan yang cepat dalam bisnis menuntut mereka harus lebih dapat menyesuaikan diri, memiliki ketahanan dalam bersaing, sanggup melaksanakan pergantian arah dengan cepat serta memusatkan atensi pada konsumen. Dalam atmosfer bisnis semacam saat ini ini industri wajib dapat jadi mitra kerja yang profesional untuk para konsumen ditengah persaingan yang terus menjadi ketat. Industri konveksi yang dalam persaingannya yakni mengenai bahan- bahan semacam pakaian, celana serta lain- lain, disaat ini seluruhnya beracuan pada pengeluaran bahan baku selaku pertimbangan buat pembuatan produk supaya bisa diterima oleh publik. CV. Kembar Jaya Kreatif merupakan salah satu industri konveksi yang ada di Indonesia, tepatnya di daerah Cicadas Bandung Utara. Perusahaan ini berdiri sejak tahun 2011. CV. Kembar Jaya Kreatif berfokus pada produksi pakaian dari kaos, jaket dan kemeja. CV. Kembar Jaya Kreatif dapat memproduksi kaos, jaket dan kemeja lebih dari 3000 produk per tahun

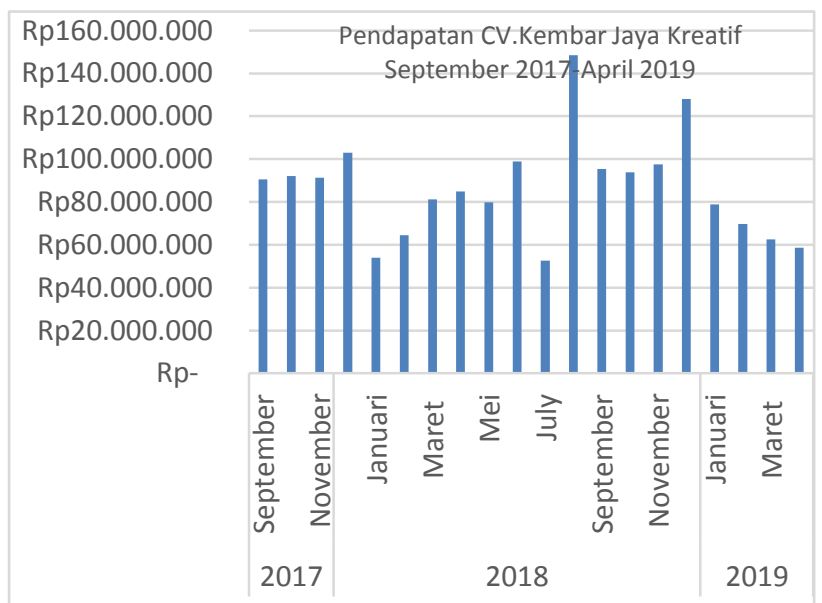

Gambar 1. Pendapatan CV. Kembar Jaya Kreatif

\section{METODE PENELITIAN}

\section{II.1 Analisis Lingkungan Internal}

Analisis Lingkungan internal pada perushaan CV. Kembar Jaya Kreatif memiliki tujuan untuk menyusun strategi yang digunakan untuk melakukan kegiatan pemasaran yang harus dilakukan perusahaan. Analisis ini menghasilkan kelebihan dan kelamahan dari perusahaan CV. Kembar Jaya Kreatif yang digunakan pada matriks IFE dan matriks analisis SWOT. Dalam analisis ini dibutuhkan faktor - faktor sebagai berikut :

- Manajemen

- Wawancara konsumen

- Segmenting, Targeting dan Positioning

- Bauran pemasaran produk

\section{II.2 Analisis Lingkungan Eksternal}

Bagian analisis eksternal pada perusahaan CV. Kembar Jaya Kreatif memiliki tujuan untuk membuat alternatif strategi pemasarah yang harus diterapkan oleh CV. Kembar Jaya Kreatif. Analisis ini akan menghasilkan faktor peluang dan ancaman dari lingkungan luar perusahaan CV. Kembar Jaya Kreatif yang digunakan pada matriks EFE dan matriks analisis SWOT. Faktor - faktor yang diperlukan untuk menyusun analisis ini berdasarkan David (2012) :

- Kekuatan ekonomi

- Kekuatan soisal, budaya, demografi serta lingkungan

- Kekuatan politik pemerintah serta hukum

- Kekuatan teknologi

- Kekuatan kompetitif

\section{II.3 Matrik IFE Dan Matrik EFE}

Matrik Internal Factor Evaluation (IFE)

- Matrik IFE hendak digunakan buat mengenali aspek- aspek internal industri semacam keunggulan serta kelemahan industri yang diaangap hendak mempengaruhi terhadap industry (David, 2004)

- Matrik External Factor Evaluation (EFE)

Matrik EFE digunakan buat mengenali aspek- aspek eksternal industri. Matrik EFE hendak memerlukan informasi eknomi, sosial, demografi, area serta budaya, politik, hukum serta pemerintah, teknologi, serta kekuatan kompetitif buat menyusun strategi (David, 2004)

\section{II.4 Matrik Internal External (IE)}

Matrik IE digunakan untuk mengetahui posisi Strategic Bussines Unit perusahaan yang terdiri atas 9 posisi. Matrik IE teridiri dari 2 bagian yaitu sumbu X 
yang menujukan skor dari matrik IFE dan sumbu $\mathrm{Y}$ yang menunjukan skor dari matrik EFE.

\section{II.5 Analisis SWOT}

(J.Salusu, $2000: 35$ ) tentang analisis matriks SWOT menggunakan beberapa strategi, yakni:

a. Strategi S.O, yakni menggunakan kesempatan yang terdapat dengan keunggulan perusahaan (comparative advantage comparative)

b. Strategi S.T, ialah memobilisasi sebagian keunggulan buat menggapai target (mobilization)

c. Strategi W.O, adalah memilah aspek mana yang dipacu serta aspek mana yang ditunda (investmen/ divestmen)

d. Strategi W.T, yakni butuh kewaspadaan dalam menggapai target (damage control)

\section{II.6 Matriks QSPM}

Metode QSPM dirancang untuk memastikan kemenarikan relatif serta mengevaluasi pilihan- opsi strategi alternatif yang bisa dilaksanakan secara objektif, bersumber pada faktor- faktor sukses internal serta eksternal yang sudah diidentifikasikan pada matriks EFE serta IFE sebelumnya. QSPM ialah matriks sesi akhir dalam kerangka kerja analisis perumusan strategi. Metode ini secara jelas membuktikan strategi alternatif yang sangat baik buat diseleksi (Purwanto, 2008). Dari Umar dan Purwanto (2008), terdapat 6 sesi yang wajib dicoba dalam membuat QSPM, ialah:

1. Membuat catatan kekuatan- kelemahan industry (internal faktor) serta ancamankesempatan (eksternal faktor) yang diambil langsung dari amtriks EFE serta IFE.

2. Bagikan bobot untuk tiap- tiap faktor internal serta faktor eksternal. Bobot ini, wajib identik dengan bobot yang diberikan pada matriks EFE serta IFE.

3. Tuliskan alternatif strategi yang dihasilkan dalam matriks SWOT.

4. Apabila faktor yang bersangkutan terdapat pengaruhnya terhadap alternatif strategi yang tengah dipertimbangkan bagikan nilai AS (Atractiveness Score) yang berkisar antara 1 hingga dengan 4 :

- $\quad$ nilai $1=$ tidak menarik
- $\quad$ nilai 2 = agak menarik

- $\quad$ nilai $3=$ secara logis menarik

- nilai $4=$ sangat menarik.

5. Hitung Total Atractiveness Score (TAS) dengan metode mengalikan bobot dengan Atractiveness Score (AS). Total Atractiveness Score membuktikan Relative Atractiveness dari tiap- tiap alternatif.

Hitung nilai totalnya TAS pada masing- masing kolom QSPM. Nilai terbanyak membuktikan jika alternatif jadi opsi utama serta nilai TAS terkecil membuktikan jika alternatif strategi yang dipilih terkahir. Wujud dasar QSPM bisa diilustrasikan pada gambar 2

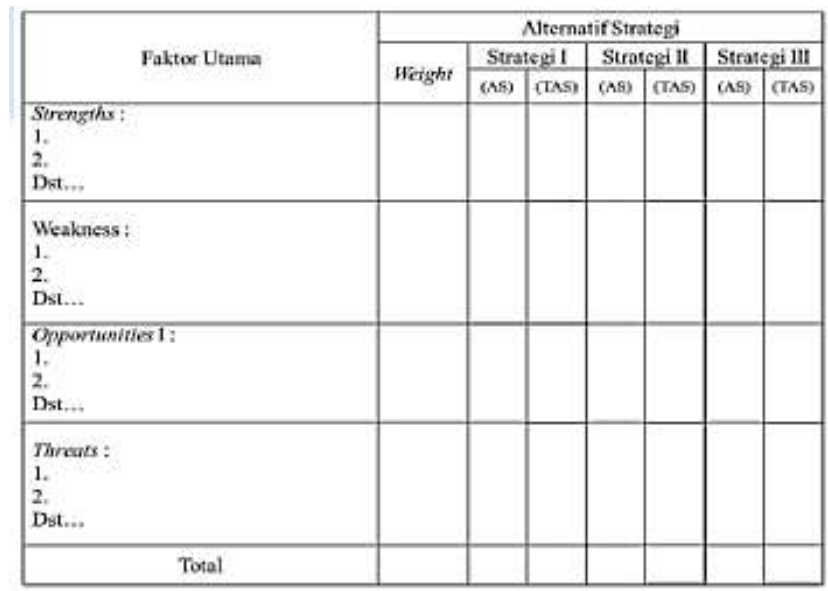

Gambar 2. Contoh Matrik QSPM

Dalam menentukan alternatif strategi pemasarannya CV. Kembar Jaya Kreatif akan menggunakan analisis matriks SWOT, dengan metode menganalisis faktor internal serta eksternal yang mempengaruhi terhadap industri CV. Kembar Jaya Kreatif. Analisis tersebut akan diolah memakai matrik IFE serta EFE yang bermanfaat untuk memastikan bobot serta rating faktor faktor aspek yang terdapat. Matrik IFE serta EFE hendak menciptakan matrik IE yang digunakan untuk mengenali tipe strategi pemasaran serta menciptakan matrik SWOT. Setelah mendapat kan alternatif strategi dari matrik SWOT dilanjutkan dengan pengambilan keputusan strategi dengan matrik QSPM dengan cara mencari ranking dari alternatif strategi yang didapat dari Matrik SWOT. 


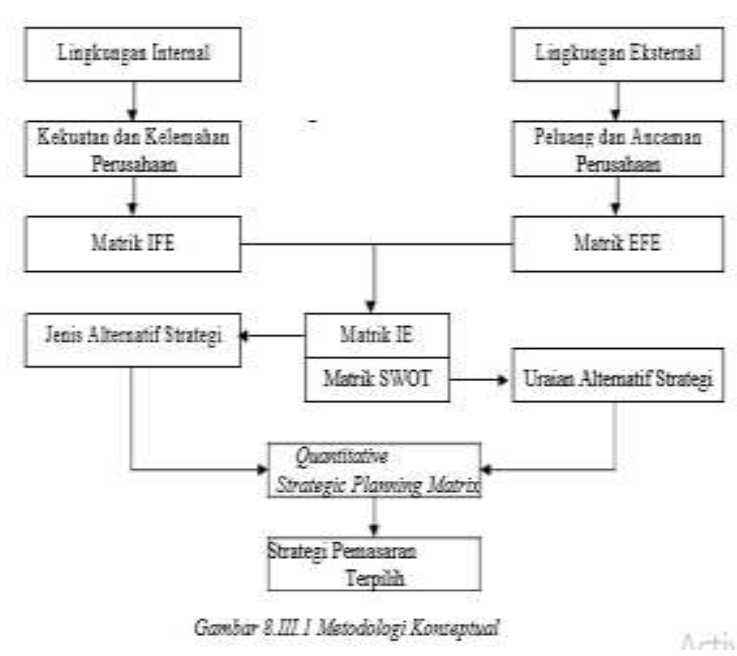

Gambar 3. Metodologi Konseptual

\section{HASIL DAN PEMBAHASAN}

\section{Isi Hasil dan Pembahasan}

\section{III.1 Analisis Matrik IFE}

Faktor Internal yang mempengaruhi CV. Kembar Jaya Kreatif terdiri dari Keunggulan dan kelemahan akan digunakan untuk menyusun Matrik IFE berserta dengan Bobot dan rating.

Tabel 1 Matrik IFE

Dapat dilihat pada perhitungan Bobot dan

\begin{tabular}{|c|c|c|c|c|}
\hline \multirow{2}{*}{ No } & Matrik IFE & RATING & BOBOT & SKOR \\
\hline & \multicolumn{4}{|c|}{ Keunggulan CV. KJK } \\
\hline 1 & $\begin{array}{l}\text { Memiliki harga yang } \\
\text { kompetitif }\end{array}$ & 3.000 & 0.113 & 0.340 \\
\hline 2 & Produk Berkualitas & 4.000 & 0.151 & 0.604 \\
\hline 3 & $\begin{array}{l}\text { Memiliki pelayanan } \\
\text { yang baik }\end{array}$ & 3.500 & 0.132 & 0.462 \\
\hline 4 & $\begin{array}{l}\text { Menguasai } \\
\text { segmentasi geografi }\end{array}$ & 3.500 & 0.132 & 0.462 \\
\hline 5 & $\begin{array}{ll}\text { Efesiensi } & \text { Waktu } \\
\text { Pengerjaan } & \\
\end{array}$ & 2.500 & 0.094 & 0.236 \\
\hline \multicolumn{5}{|c|}{ Kelemahan CV.KJK } \\
\hline 1 & $\begin{array}{ll}\begin{array}{l}\text { Lokasi } \\
\text { strategis }\end{array} & \text { Kurang } \\
\end{array}$ & 1.000 & 0.038 & 0.038 \\
\hline 2 & $\begin{array}{ll}\text { Promosi } & \text { Belum } \\
\text { maksimal } & \\
\end{array}$ & 1.500 & 0.057 & 0.085 \\
\hline 3 & $\begin{array}{l}\text { Tidak ada evaluasi } \\
\text { terhadap } \\
\text { permasalahan } \\
\text { internal }\end{array}$ & 1.500 & 0.057 & 0.085 \\
\hline 4 & $\begin{array}{l}\text { Tidak Melayani } \\
\text { dalam jumlah kecil }\end{array}$ & 2.000 & 0.075 & 0.151 \\
\hline 5 & $\begin{array}{l}\text { Kurang } \\
\text { memanfaatkan } \\
\text { teknologi }\end{array}$ & 2.000 & 0.075 & 0.151 \\
\hline 6 & $\begin{array}{l}\text { Pendidikan karyawan } \\
\text { relatif rendah }\end{array}$ & 2.000 & 0.075 & 0.151 \\
\hline & Total & 26.500 & 1.000 & 2.764 \\
\hline
\end{tabular}

Rating pada Matrik IFE diperoleh total skor sebesar 2,764. Skor Bobot total berada diatas nilai 2,5 yang menandakan bahwa kondisi perusahaan secara Internal masih sangat kuat.

\section{III.2 Analisis Matrik EFE}

Faktor external yang mempengaruhi CV. Kembar Jaya Kreatif terdiri dari peluang dan ancaman yang akan digunakan untuk menyusun Matrik EFE berserta dengan bobot dan rating.

\begin{tabular}{|c|c|c|c|c|}
\hline \multirow{2}{*}{ No } & Matrik EFE & RATING & BOBOT & SKOR \\
\hline & \multicolumn{4}{|l|}{ Peluang } \\
\hline 1 & $\begin{array}{l}\text { Semakin Bertambah } \\
\text { industri konveksi pasar } \\
\text { semakin luas }\end{array}$ & 3 & 0.122449 & 0.367347 \\
\hline 2 & $\begin{array}{lr}\text { Memanfaatkan } & \\
\text { perkembangan } & \text { teknologi } \\
\text { sebagai alat } & \text { untuk } \\
\text { melakukan } & \text { kegiatan } \\
\text { pemasaran } & \text { akan } \\
\text { membantu } & \\
\text { berkembangnya } & \\
\text { Perusahaan } & \\
\end{array}$ & 3.5 & 0.142857 & 0.5 \\
\hline 3 & $\begin{array}{l}\text { UMKM di Jawa Barat } \\
\text { didukung oleh pemerintah }\end{array}$ & 2.5 & 0.102041 & 0.255102 \\
\hline 4 & $\begin{array}{l}\text { Membangun hubungan } \\
\text { baik dengan pelanggan }\end{array}$ & 3 & 0.122449 & 0.367347 \\
\hline 5 & Terbukanya pasar bebas & 4 & 0.163265 & 0.653061 \\
\hline & Ancaman & & & \\
\hline 1 & $\begin{array}{l}\text { Timbulnya kompetitor } \\
\text { baru }\end{array}$ & 1.5 & 0.061224 & 0.091837 \\
\hline 2 & $\begin{array}{l}\text { Perusahaan konveksi } \\
\text { dengan modal besar bisa } \\
\text { memonopoli }\end{array}$ & 1.5 & 0.061224 & 0.091837 \\
\hline 3 & $\begin{array}{l}\text { Masyarakat memilih } \\
\text { konveksi kepercayaannya }\end{array}$ & 2 & 0.081633 & 0.163265 \\
\hline 4 & $\begin{array}{l}\text { Meningkatnya harga } \\
\text { bahan baku }\end{array}$ & 1.5 & 0.061224 & 0.091837 \\
\hline 5 & $\begin{array}{l}\text { Masyarakat banyak yang } \\
\text { memilih bahan dengan } \\
\text { serat plastic }\end{array}$ & 2 & 0.081633 & 0.163265 \\
\hline Total & & 26.5 & 1 & 2.744898 \\
\hline
\end{tabular}

Tabel 2 Matrik EFE

Dapat dilihat pada perhitungan Bobot dan Rating pada Matrik EFE diperoleh total skor sebesar 2, 744. Skor total terletak diatas nilai 2, 5 yang menunjukkan jika keadaan industri CV. Kembar Jaya Kreatif bisa menangani faktor external dengan menggunakan kesempatan yang terdapat serta bisa menangani ancaman yang tiba.

\section{III.3 Analisis Strategi Matrik IE}

Tahap yang dicoba selanjutanya merupakan menyusun hasil dari matrik IFE serta EFE memakai matrik IE (Internal- External) yang berfungsi untuk mengenali posisi untuk memastikan strategi pemasaran. 
Tabel 3 Matrik IE

\begin{tabular}{|l|l|l|l|l|l|}
\hline \multirow{2}{*}{\multicolumn{2}{|c|}{ Matrik IE }} & \multicolumn{3}{l|}{ Skor IFE (2,764) } \\
\cline { 4 - 6 } \multicolumn{1}{|l|}{} & $3,0-4,0$ & $2,0-2,99$ & $1,0-1,99$ \\
\hline \multirow{4}{*}{ Skor } & $2,0-$ & Kuat & Rata-rata & Lemah \\
\cline { 2 - 6 } & $3,0-4,0$ & Tinggi & I & II & III \\
\cline { 2 - 6 } EFE & 2,99 & Sedang & IV & V & VI \\
\cline { 2 - 6 }$(2,7$ & $1,0-$ & & & & \\
$44)$ & 1,99 & Lemah & VII & VIII & IX \\
\hline
\end{tabular}

Hasil dari matrik IFE mencapai 2,764 dan hasil dari matrik EFE 2,744 sehingga menunjukan bahwa posisi CV. Kembar Jaya Kreatif berada di posisi II yang berarti grow and build strategy. Strategi diatas menunjukan perusahaan membutuhkan strategi untuk berkembang menjadi baik, jenis strategi yang direkomendasikan adalah pertumbuhan integrasi vertikal. Strategi integrasi vertikal dilaksanakan dengan cara menyesuaikan harga, untuk development product lama, menambahkan kualitas produk dan meningkatkan akses ke pasar yang lebih luas.

\section{IV.4 Analisis Matrik SWOT}

Setelah menganalisis mengenakan Matrik IE, sesi berikutnya merupakan menyusun alternatif strategi memakai matrik SWOT.

1. Strategi SO (Strength-Opprtunities)

- Memanfaatkan teknologi yang terdapat untuk melaksanakan aktivitas pemasaran serta menjual produk secara online semacam lewat media sosial serta $e$ commerce (S1, S3, O1, O2, O4)

2. Strategi ST (Strength - Threat)

- Fokus di tingkatkan pada development product serta mutu produk supaya konsumen tidak berpindah konveksi lain( S1, S2, S5, T3, T4, T5)

\section{Strategi WO (Weakness - Opportunities)}

- Membuka cabang dengan tempat yang lebih strategis supaya calon konsumen baru tidak sulit untuk mendapatkan letak CV. Kembar Jaya Kreatif (W1, W2, O1, O4)

- Memberi pelatihan, pengetahuan serta penilaian lebih terhadap karyawan (W3, W4, W6, 04)

4. Strategi WT (Weakness - Threat)

- Memberikan ikatan ataupun kedekatan yang baik terhadap supplier dari bahan ataupun distributor kain buat mengestimasi melonjak nya harga (W2, W3, T1, T4, T5)

\section{IV.5 Analisis Matrik Quantitative Strategic Planning}

Tahap akhir dari analisis ini adalah menentukan strategi pemasaran pada CV. Kembar Jaya Kreatif menggunakan matrik Quantitative Strategic Planning. Matrik ini akan melanjutkan hasil dari Matrik SWOT. Berdasarkan analisis matrik SWOT terdapat 5 rumusan strategi. Setelah rumusan strategi ditemukan tahap selanjutnya adalah mengihtung total attractiveness score (TAS). Nilai TAS didapat dari perkalian antara rata - rata bobot dengan nilai attractiveness score (AS). Hasil dari seluruh TAS akan disusun dari yang terbesar hingga yang terkecil lalu akan dipilih nilai TAS terbesar sebagai strategi yang harus diutamakan oleh CV. Kembar Jaya Kreatif.

Tabel 4. Matrik QSPM

\begin{tabular}{|c|l|c|c|}
\hline No & \multicolumn{1}{|c|}{ Alternatif Strategi } & $\begin{array}{c}\text { Total } \\
\text { TAS }\end{array}$ & Peringkat \\
\hline 1 & $\begin{array}{l}\text { Strategi 1 : Memanfaatkan teknologi yang } \\
\text { ada untuk melakukan kegiatan pemasaran } \\
\text { dan menjual produk secara online seperti } \\
\text { melalui media sosial dan } \text {-commerce }\end{array}$ & 6.303 & 1 \\
\hline 2 & $\begin{array}{l}\text { Strategi 2 Fokus di tingkatkan pada } \\
\text { development product dan kualitas produk } \\
\text { agar konsumen tidak berpindah konveksi } \\
\text { lain }\end{array}$ & 5.970 & 2 \\
\hline 3 & $\begin{array}{l}\text { Strategi 3 Memberikan pelatihan, wawasan } \\
\text { dan evaluasi lebih terhadap para karyawan }\end{array}$ & 5.449 & 5 \\
\hline 4 & $\begin{array}{l}\text { Strategi 4. Membuka cabang dengan tempat } \\
\text { yang lebih strategis agar calon konsumen } \\
\text { baru tidak sulit untuk menemukan lokasi } \\
\text { CV. Kembar Jaya Kreatif }\end{array}$ & 5.639 & 3 \\
\hline 5 & $\begin{array}{l}\text { Strategi 5. Memberikan hubungan atau } \\
\text { relasi yang baik terhadap supplier dari } \\
\text { bahan atau distributor kain untuk } \\
\text { mengantisipasi melonjak nya harga }\end{array}$ & 5.526 & 4 \\
\hline
\end{tabular}

\section{KESIMPULAN}

Bersumber pada rumusan permasalahan yang terdapat pada riset, bisa disimpulkan kalau hasil dari riset ini merupakan: 
1. Hasil analisis matriks IE menunjukkan jika posisi CV. Kembar Jaya Kreatif terletak pada sel II, ialah strategi yang berkembang serta membangun. Strategi yang sesuai yaitu merendahkan harga, meningkatkan produk, tingkatkan mutu produk, ataupun tingkatkan akses ke pasar yang lebih luas. Hasil tersebut didapat dari hasil skor matriks IFE serta matriks EFE yang sebesar 2, 764 serta 2,744 .

2. Alternatif strategi pemasaran yang dapat dilakukan oleh CV. Kembar Jaya Kreatif dalam melaksanakan usahanya yaitu :

a. Menggunakan teknologi yang ada buat melaksanakan aktivitas pemasaran serta menjual produk secara online semacam lewat media sosial serta - commerce.

b. Fokus di tingkatkan pada development product serta mutu produk supaya konsumen tidak berpindah konveksi lain.

c. Membagikan pelatihan, pengetahuan, serta penilaian lebih terhadap para karyawan.

d. Membuka cabang dengan tempat yang lebih strategis supaya calon konsumen baru tidak sulit untuk mendapatkan letak CV. Kembar Jaya Kreatif.

Membagikan ikatan ataupun kedekatan yang baik terhadap supplier dari bahan ataupun distributor kain buat mengestimasi melonjak nya harga.

3. Hasil analisis QSPM memperoleh 3 saran strategi pemasaran yang bisa yang

bisa diimplementasian oleh CV. Kembar Jaya Kreatif. Berikut ialah 3 saran strategi pemasaran tersebut bersumber pada nilai TAS terbanyak:

a. Menggunakan teknologi yang ada untuk melaksanakan aktivitas pemasaran serta menjual produk secara online semacam lewat media sosial serta $e$ - commerce dengan nilai TAS sebesar 6, 303 .

b. Fokus di tingkatkan pada development product serta mutu produk supaya konsumen tidak berpindah konveksi lain dengan nilai TAS sebesar 5, 970 . c. Membuka cabang dengan tempat yang lebih strategis supaya calon konsumen baru tidak sulit untuk mendapatkan letak CV. Kembar Jaya Kreatif dengan nilai TAS sebesar 5, 639.

\section{Daftar Pustaka}

David, F.R. (2012) Strategic Management. Jakarta, Salemba Empat

Umar. 2001. Strategic Management in Action : Konsep, Teori, dan Teknik Menganalisis Manajemen Strategis Strategic Business Unit Berdasarkan konsep Michael R. Porter, Fred R. David, dan Wheelen-Hunger. PT. Gramedia Pustaka Utama, Jakarta

Kotler dan Keller (2016). Marketing Management. Jilid 1. Edisi Kelima Belas E. Pearson Education Limited.

Kotler, Philip G., Armstrong (2008). Prinsip-Prinsip Pemasaran, Edisi Kedua Belas, Jilid 1. Erlangga, Jakarta.

Rangkuti, Freddy.2017. Teknik Membedah Kasus Bisnis Analisis SWOT. PT. Gramedia Pustaka Utama, Jakarta.

Aris Nugroho (2016) Analisis Strategi Pemasaran Dengan Menggunakan Metode Quantitative Strategic Planning Matrix (QSPM) Pada Usaha Mebel Di Universitas Muhammadiyah Surakarta : eprints.ums.ac.id

Hany S., Mas'ud E., Imam S. (2016) Analisis Strategi Pemasaran Menggunakan Matriks SWOT dan QSPM (Studi Kasus: Restoran WS Soekarno Hatta Malang) Di Universitas Brawijaya Malang : industria.ub.ac.id.

Harold L. S., Farah A, (2014) Formulasi dan Pemilihan Strategi Bisnis Menggunakan Analisis SWOT dan Matriks QSPM pada Perusahaan Jasa Konsultasi Lingkungan CV JO Lestari Tahun 2014 Di Universitas 
FE Universitas Maritim Raja Ali Haji

Telkom: openlibrary.telkomuniversity.ac.id

Teguh B., Chandra P. (2014) Analisis Strategi Pengembangan Bisnis PPOB KIPO Menggunakan Analisis SWOT Dan QSPM Di Universitas Muhammadiyah Malang : ejournal.umm.ac.id

Clara A. S., Charly H. (2017) Perumusan Strategi Pemasaran Menggunakan Metode QSPM pada Bisnis Sambal Noesantara Di Universitas Ciputra Surabaya : dspace.uc.ac.id

Data Pertumbuhan Industri Konveksi Pakaian Jadi di Indonesia, kemenperin (2018). Diakses pada : kemenperin.go.id

Data perilaku Pengguna Internet Indonesia, (Asosiasi Penyelenggara Jasa Internet Indonesia 2018). Diakses pada : apjii.or. 